\title{
Grounding Impedance Measurement of High Speed Railway Integrated Grounding System
}

\author{
Zhang Yi, Jianguo Wang, Yadong Fan, Mi Zhou, Li Cai \\ School of Electrical Engineering, Wuhan University, Wuhan, China \\ Email: yitiaxiao@163.com, wjg@whu.edu.cn, ydfan@whu.edu.cn, zhoumi927@163.com, caili@whu.edu.cn
}

Received January 2015

\begin{abstract}
The high-speed railway integrated grounding system is the basic guarantee for the safe and stable operation of the railway. It is the world's largest long-distance horizontally elongated joint grounding system, which stretches the length of hundreds to thousands of kilometers, and its structure is not only different from power station and substation grounding system, but also different from the transmission line tower, lightning rod and other small grounding devices. There is little research information on the grounding impedance of high-speed railway integrated grounding system. This paper adopted 0.618 compensation method and reverse away method respectively, measured a section of high-speed railway integrated grounding system grounding impedance by JD16 and CA6425. Measurement results are in good agreement using those two type instrument. By using 0.618 compensation method, the measurement result will be gradually converged at 0.3 $\Omega$ with the increasing of current electrode distance, which is the real grounding impedance of integrated grounding system. By using reverse away method, the maximum measurement result difference is less than $0.024 \Omega$ with the lead of current electrode distance increasing. The measurement results will be rapidly converged $0.25 \Omega$. The results showed that the reverse away method is helpful to shorten the length of current electrode wiring. The measurement error will be small when the current electrode wiring is longer.
\end{abstract}

\section{Keywords}

High-Speed Railway, Integrated Grounding System, Grounding Impedance

\section{Introduction}

Over the past few years, China has invested a lot of manpower and material resources in the development and construction of high speed railway, whose operation speed has been improved to $350 \mathrm{~km} / \mathrm{h}$ in service. In order to reduce the potential difference and electromagnetic interference between each professional system, high-speed railway in China have adopted the integrated grounding system [1]-[4]. By laying the run-through ground wire along the two sides of railway, high-speed railway integrated grounding system fuses traction power supply return system, power service system, communication signal system, buildings, road bed, platform, bridges, tunnels, sound barrier and other electrical and electronic information system together, forming a huge-scale long-distance horizontal grounding system, which is the basic guarantee and important measure to maintain high speed 
railway safe and reliable operation, ensure operating personnel and electrical equipment safety.

At present, the domestic and foreign research and analysis about the grounding performance of grounding body have been quite comprehensive, but they mainly focused in the power system grounding. Railway integrated grounding system is a longitudinal through large horizontal grounding body, whose structure is not only different from power station and substation grounding system, but also different from the transmission line tower, lightning rod and other small grounding devices. Many existing research results of power system grounding body can not be directly applied to the railway integrated grounding field. High-speed railway integrated grounding system is a new grounding body, little information is about it, whose grounding impedance characteristics need to be deeply studied.

This paper respectively adopted 0.618 compensation method and reverse away method, measured a section of high-speed railway integrated grounding system grounding impedance [5] [6]. The results showed that the reverse away method is helpful to shorten the length of current electrode wiring.

\section{Grounding Impedance Measurement of High-Speed Integrated Grounding System}

\subsection{Measurement Method}

Figure 1 is the 0.618 compensation method measurement schematic diagram, where the voltage electrode distance $d_{P G}$ between the voltage electrode $P$ and the integrated grounding system equals to 0.618 the current electrode distance $\mathrm{d}_{\mathrm{CG}}, \mathrm{d}_{\mathrm{CG}}$ is the distance between the current electrode $\mathrm{C}$ and the integrated grounding system. The current electrode $C$, the voltage electrode $P$ and the current injected point $G$ are in a straight line as shown in Figure 1.

Figure 2 is the reverse away method measurement schematic diagram, where the voltage electrode distance $\mathrm{d}_{\mathrm{PG} 1}=0.5 \mathrm{~d}_{\mathrm{CG}}$. The straight line $\mathrm{d}_{\mathrm{CG}}$ and the straight line $\mathrm{d}_{\mathrm{PG} 1}$ are the same straight line as shown in Figure 2.

These straight line are perpendicular to the railway integrated grounding system. The current and potential testing circuit can be accurately set by the global positioning system (GPS).

\subsection{Measurement Position and Measurement Instrument}

This paper carried out the comparison of grounding impedance measurement between the 0.618 compensation method and reverse away method in plain embankment section of uniform soil resistivity in Wuhan-Guangzhou high-speed railway section DK1274.331. The width of run-through ground wire of railway integrated grounding system is about $26 \mathrm{~m}$. The current injection point is in the leading out terminal of integrated grounding wire in the right of railway cable trench, as shown in Figure 3.

The measuring instrument is four terminal grounding resistance tester, as shown in Figure 4. There are JD16type grounding resistance tester (Hereinafter referred to as the JD16) and digital grounding resistance meter

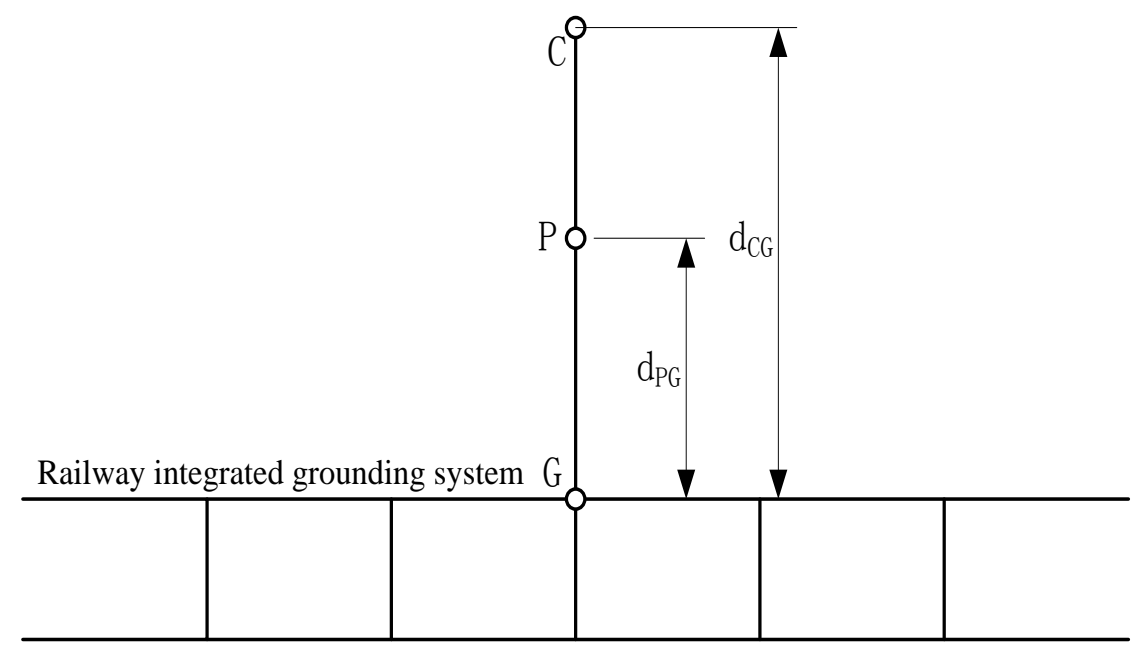

Figure 1. 0.618 compensation method. 


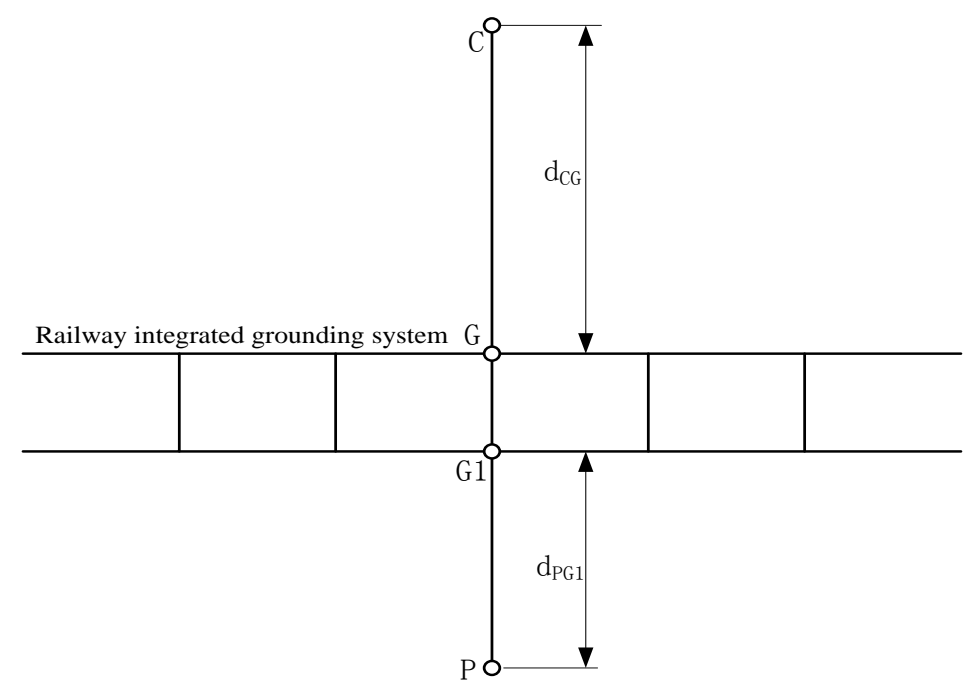

Figure 2. Reverse away method.
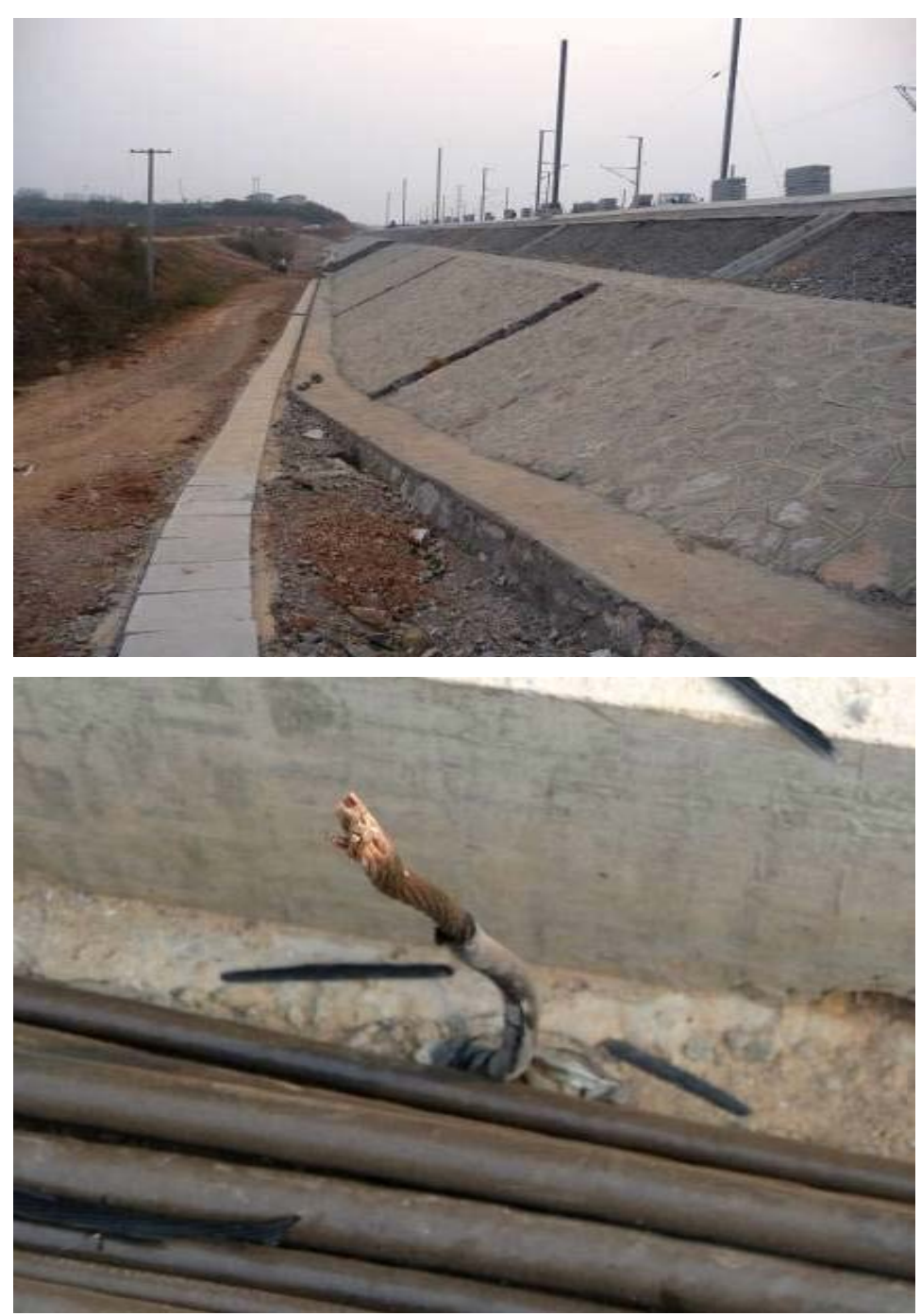

Figure 3. Field test images. 


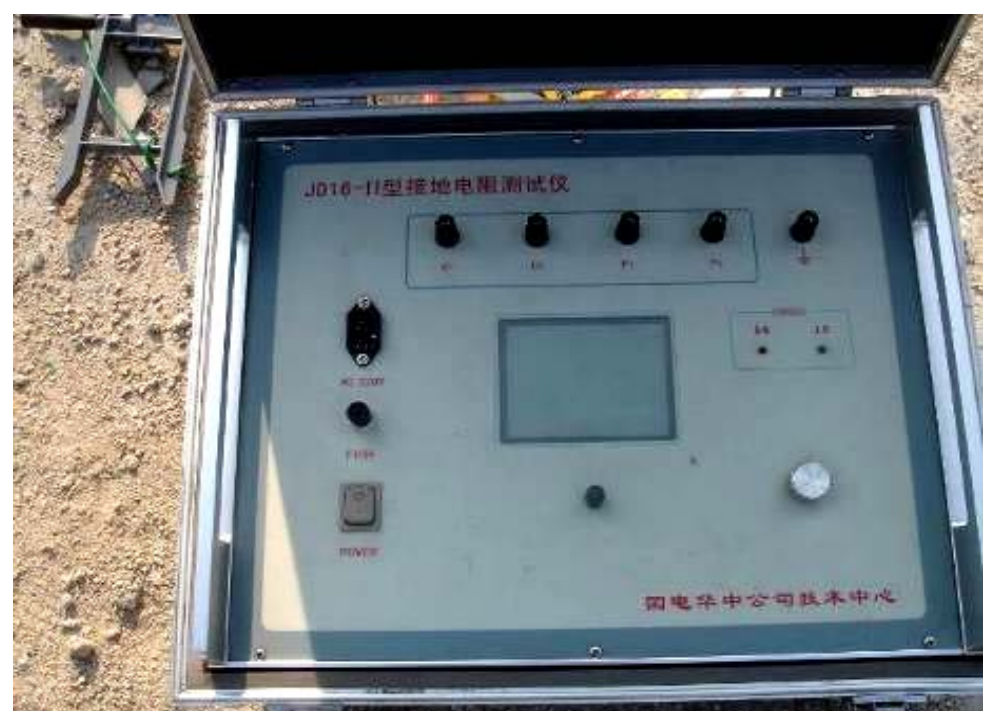

(a)

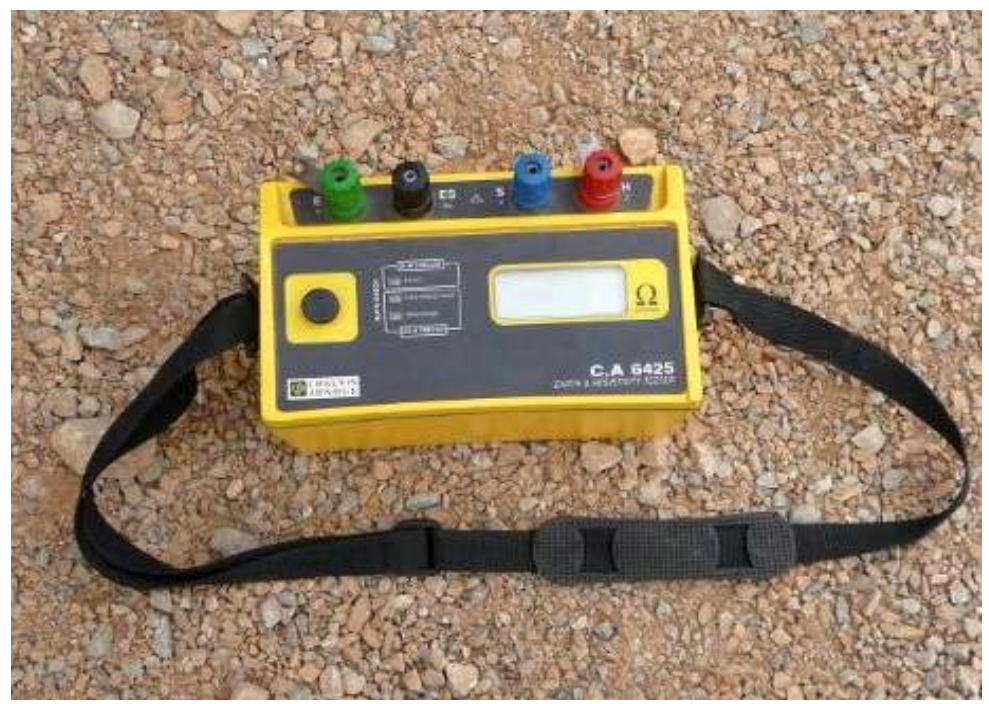

(b)

Figure 4. Measurement instrument. (a) JD 16. (b) CA6425.

(hereinafter referred to as the CA6425).

JD16 are tested with the test current $47.5 \mathrm{~Hz}$ and $52.5 \mathrm{~Hz}$, reading the average test results. It measured grounding impedance $\mathrm{Z}$ and its real part $\mathrm{R}$ and imaginary part of $\mathrm{X}$, whose measurement range of grounding impedance is 0 - $30 \mathrm{k} \Omega$, and measurement error is less than $1 \%$. CA6425 measured grounding impedance, soil resistivity and electrical integrity, and its measurement range is $0-1999 \Omega$, accuracy is $2 \%$, the resolution is $0.01 \Omega$.

\section{Measurement Results}

\subsection{Compensation Method Measurement Results}

0.618 compensation method measurement results of railway integrated grounding system's grounding impedance are shown in Figure 5. As you can see from Figure 5, JD16 and CA6425 measurement results are in good agreement, the maximum measurement result difference is less than $0.04 \Omega$. With the lead of current electrode distance increasing, the measurement results will be gradually converged at $0.3 \Omega$ which is the real grounding impendence of integrated grounding system.

When the current electrode wiring dCG is $36 \mathrm{~m}$, measurement result using JD16 is $0.783 \Omega$. When the current 
electrode wiring dCG is $266 \mathrm{~m}$, measurement result using JD16 is $0.342 \Omega$. When the current electrode wiring dCG is $710 \mathrm{~m}$, measurement result using JD16 is $0.285 \Omega$. By JD16 measurement difference of current electrode wiring between $430 \mathrm{~m}$ and $710 \mathrm{~m}$ is less than $0.016 \Omega$. The current electrode distance increase is helpful to get the small measurement error.

Reverse away method measurement results of railway integrated grounding system's grounding impedance are shown in Figure 6. As you can see from Figure 6, JD16 and CA6425 measurement results are in good agreement, the maximum measurement result difference is less than $0.024 \Omega$. With the lead of current electrode distance increasing, the measurement results will be rapidly converged.

When the current electrode wiring distance of reverse away method measurement railway integrated grounding system's grounding impedance is above $100 \mathrm{~m}$, the difference is less than $0.01 \Omega$.

\section{Discussion}

The 0.618 compensation method measurement results with short current electrode wiring are bigger. The longer current electrode wiring can reduce the error brought by the zero potential point, and the measurement results are beginning to converge. The increased current electrode wiring length facilitates the convergence measure

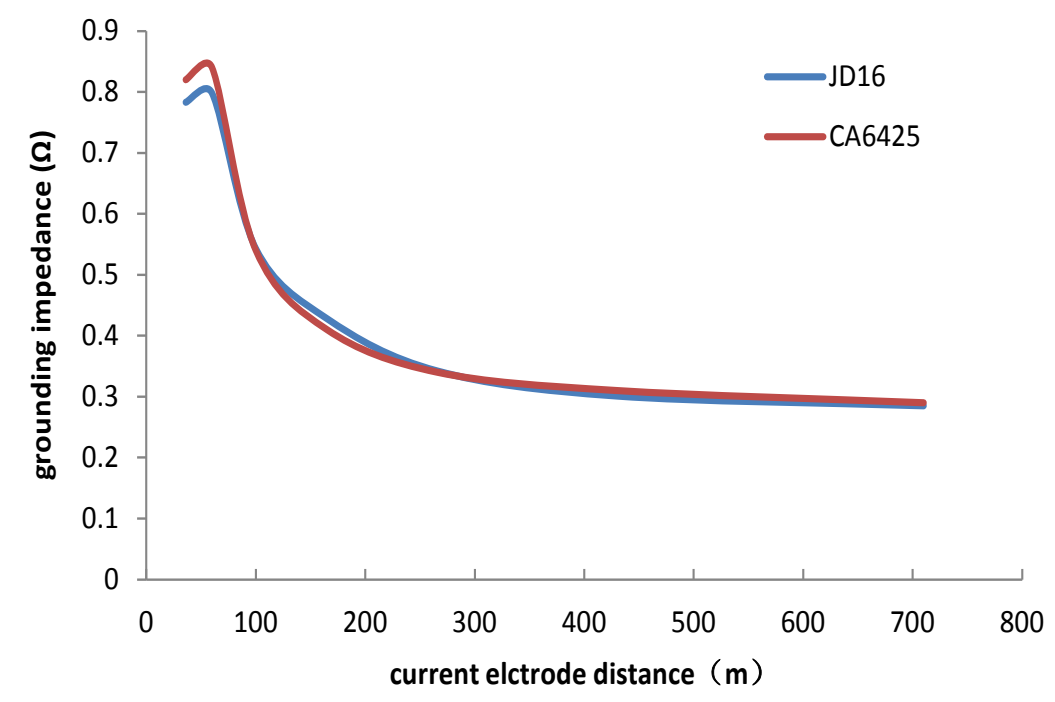

Figure 5. 0.618 compensation method measurement results.

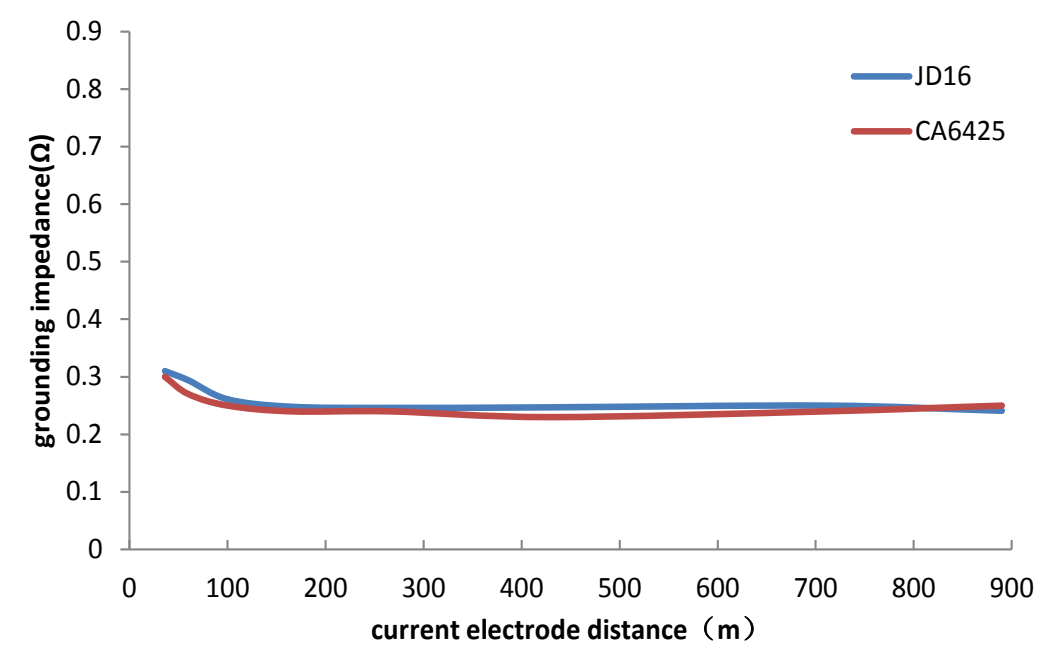

Figure 6. Reverse away method measurement results. 
ment results when the compensation method is used.

The 0.618 compensation method in the theoretical is taking the 0.5 current electrode length as the zero potential point, through potential compensation to realize the inherent error compensation of the voltage electrode position. Compared to railway integrated grounding system of long distance run-through grounding wire, the current electrode is very small vertical grounding electrode. The current field distribution distortion is serious when the current electrode wiring is short. The zero potential position has big error, The error will be small when the current electrode wiring is longer.

When the current electrode wiring is $36 \mathrm{~m}$, the measurement result of reverse away method is $0.31 \Omega$. While the current electrode wiring is $430 \mathrm{~m}$, the measurement result of compensation method is $0.301 \Omega$. When the current electrode wiring is $60 \mathrm{~m}$, the measurement result of reverse away method is $0.294 \Omega$. While the current electrode wiring is $710 \mathrm{~m}$, the measurement result of compensation method is $0.29 \Omega$. The measurement results of the two methods are almost the same.

When the current electrode wiring is the same, compared to the compensation method, the measurement result of the reverse away method converges quickly. The reverse away method is helpful to reduce the current electrode wiring.

But the measurement result of the reverse away method is smaller than the measurement result of the compensation method, which is similar to [7]. The amendment will be completed in the future work.

\section{Conclusions}

This paper respectively adopted 0.618 compensation method and reverse away method by two types of instruments, and measured a section of high-speed railway integrated grounding system grounding impedance.

1) Measurement results are in good agreement using the two types of instruments by using 0.618 compensation method and reverse away method.

2) By using 0.618 compensation method, the measurement result will be gradually converged at $0.3 \Omega$. By using reverse away method, the measurement results will be rapidly converged $0.25 \Omega$. Convergence rate of reverse away method is quicker than 0.618 compensation method.

3) The measurement result of the reverse away method is smaller than the measurement result of the 0.618 compensation method, so amendment will be considered in the future work.

4) Reverse away method is helpful to shorten the length of current electrode wiring.

\section{References}

[1] Wu, G.N., Gao, G.Q., Dong, A.P., et al. (2011) Study on the Performance of Integrated Grounding Line in High-Speed Railway. IEEE Transactions on Power Delivery, 26, 1803-1810. http://dx.doi.org/10.1109/TPWRD.2011.2117446

[2] Pan, R., Wu, M.L. and Yang, S.B. (2009) Performance of the IGS of Hefei-Nanjing Passenger Dedicated Railway. Proc. Int. Conf. Sustainable Power Generation and Supply, 1-5.

[3] Natarajan, R., Imece, A.F., Popoff, J., et al. (2001) Analysis of Grounding Systems for Electric Traction. IEEE Transactions on Power Delivery, 16, 389-393. http://dx.doi.org/10.1109/61.924816

[4] Mariscotti, A., Pozzobon, P. and Vanti, M. (2005) Distribution of the Traction Return Current in AT Electric Railway Systems. IEEE Transactions on Power Delivery, 20, 2119-2128. http://dx.doi.org/10.1109/TPWRD.2005.848721

[5] IEEE Standard No.80-2000 (2000) IEEE Guide for Safety in AC Substation Grounding.

[6] ANSI/IEEE Std. 81 (2012) Guide for Measuring Earth Resistivity, Ground Impedance, and Earth Surface Potentials of a Ground System.

[7] Wang, C., Takasima, T., Sakuta, T., et al. (1998) Grounding Resistance Measurement using Fall-of-Potential Method with Potential Probe Located in Opposite Direction to the Current Probe. IEEE Transactions on Power Delivery, 13, 1128-1135. http://dx.doi.org/10.1109/61.714472 